\title{
Calle y casa. Aprontes teóricos para una comprensión de la situación de calle desde sus actores*
}

\section{Leonardo Piña Cabrera**}

\begin{abstract}
Resumen: En este texto se propone el estudio del fenómeno de la vida en la calle a partir de la intención de visualizar a las personas que lo protagonizan como agentes, esto es como sujetos que pueden actuar y tener conciencia de su acción, perspectiva casi totalmente ausente tanto en los estudios hasta ahora realizados como en nuestros cotidianos modos de relación con ellos. Para tales efectos, su diseño se propone un acercamiento en cuatro direcciones complementarias, a saber, la aproximación a los significados dados por estos hombres y mujeres a sus experiencias de vida, el conocimiento de las prácticas e interacciones que establecen cotidianamente, su articulación en diálogo con otras retóricas de la marginación junto a las cuales co-construyen el fenómeno, y su puesta en relación con el contexto y otros procesos que lo engloban y junto a los cuales se desarrolla.
\end{abstract}

Palabras clave: situación de calle, vagabundaje, agencia.

\section{Street and home. A theoretical approach to an understanding of the homelessness from the protagonists' point of view}

\begin{abstract}
In this article, the author approaches the study of the phenomenon of homelessness from the point of view of its own protagonists, that is, agents who choose to act and are aware of their own actions; a perspective that is almost completely absent, both in the study of the homelessness as well as in our daily interactions with them. To this effect, the paper's design proposes an approach in four complementary directions: an approximation to the meaning given by homeless men and women to their own life experiences; an understanding of the behaviors and interactions that homeless establish in their daily routines; their dialogue with other discourses of marginalization interwoven in the construction of homelessness; and the relationship of homelessness with its context and other wider processes that encompass its development.
\end{abstract}

Key words: homelessness, vagancy, agency.

\footnotetext{
* Extracto del diseño de investigación doctoral aprobado, en diciembre de 2007, en el marco del Programa de Doctorado en Antropología de las Universidades de Tarapacá y Católica del Norte.

** Universidades de Tarapacá y Católica del Norte, Puerto Montt, Chile. Email: leonardopinacabrera@yahoo.es
} 


\section{Rua e casa. Aportes teóricos para uma compreensão da situação de rua de seus atores}

Resumo: Texto correspondente à discussão teórica do projeto de pesquisa de doutorado do autor, no qual se propõe estudar o fenômeno da vida nas ruas com a intenção de visualizar as pessoas que o protagonizam como agentes, ou seja, como sujeitos que podem atuar e ter consciência de sua ação, perspectiva quase completamente ausente tanto nos estudos realizados ate o momento, como em nossos modos cotidianos de relação com eles. Para este fim, a pesquisa propõe uma aproximação em quatro direções complementares, a saber, a abordagem dos significados atribuídos por esses homens e mulheres e suas experiências de vida, o conhecimento das práticas e interações que estabelecem cotidianamente, sua articulação em diálogo com outras retóricas da marginalização, junto às quais coconstroem o fenômeno, e sua aplicação em relação ao contexto e outros processos que o englobam e com os quais se desenvolve.

Palavras-chave: localização de rua, vadiagem, da agência.

Recibido: 04.09.2009

Aceptado: 02.05.2010

$* * *$

La definición por negación o ausencia que se hace de las personas que viven en situación de calle en nuestras ciudades, así como trae a colación la larga tradición de acercamientos fallidos que en torno a los pueblos indígenas y culturas tradicionales se hizo al interior de la antropología al referirlos, por ejemplo, como sociedades sin Estado o economías de subsistencia, plantea, en lo que a estos hombres y mujeres se refiere, una serie de efectos perversos, entre ellos su comprensión como sujetos sin capacidad de agencia, esto es como personas imposibilitadas de vivir de otra manera, movidas, quizá, por la inercia de sus carenciados presentes.

Resultado de un profundo desconocimiento, prejuicio y generalización, su incógnita, explicada como extensión de situaciones de deprivación, falta de oportunidades, desempleo, abandono, desórdenes mentales, alcoholismo y/o drogodependencia, e históricamente caracterizada como refractaria al trabajo y puerta de entrada al mundo del delito (o una más de sus expresiones propiamente dichas), instalando la distancia en el modo en que se los entiende como en la forma en que nos relacionamos con ellos, ha terminado por situarlos fuera de su propio rango de acción e impedido, en consecuencia, la posibilidad de visualizarlos como partes constituyentes de su fenómeno. Comprehensivamente inhabilitados para vivir de otra forma dada su extrema condición de pobreza y situados, subsiguientemente, al centro de la caridad, ya que no de la política social, tal respuesta-factor, en último término, de su infantilización-, tampoco ha supuesto cercanía, acaso compasión. Alternativa bonachona pero todavía expresión del etnocentrismo de la tribu sedentaria -o del paradigma de la vivienda, como llama el antropólogo español Manuel Delgado a lo que "pasa en los contextos sociales plenamente estructurados del adentro construido” (2007: 39)_- 
, su emergencia no ha supuesto el retroceso de su incógnita y minusvaloración sino, más bien, el refuerzo de un tipo de abordaje igualmente distanciador, toda vez que suponiendo que en la apariencia fenoménica de una práctica está su móvil, deja de avanzar en la particularización de la experiencia de y en la calle, reduciéndola a problema social, y/o de seguridad social. Y, con ello, de verlo en relación con sus otros componentes lo que impide observar, por ejemplo, el espacio para la libertad personal (y laboral) que también tendría, y el complejo desarrollo de redes y habilidades adaptativas frente a circunstancias, vitales y de contexto, altamente desfavorables. En suma, de apreciarlos en su condición de actores en propiedad.

La delgada línea, asimismo, que va desde su conceptualización como homeless, vale decir como personas cuya "condición de no tener ningún acceso al abrigo o de tener un acceso a él que es tan precario que la vida en sí misma está amenazada” (Glasser 1996: 579), hasta su reducción a problema habitacional dada su contenida situación sin techo, o de exclusión social que consigo lleva, implicando un tipo de comprensión altamente simplificador de lo real, también haría parte de este juego, esta vez no solo reduciendo a una dimensión su fenómeno o pensándolos al margen de la vida social y por acción de otros, sino privándolos de ciudadanía al aparejarla a la disposición de un sitio en la ciudad, léase domicilio conocido, que sería el encargado de proveer los derechos que, por lo mismo, no podrían tener ni se les reconoce ${ }^{1}$. Vida urbana como modelo de virtud y civilización históricamente instalado desde la colonia a partir de la real decisión de fundar ciudades, su ausencia, en el caso que acá importa, los convertiría en una suerte de contemporáneos primitivos que, incapaces de tener y/o tomar posición, tampoco tendrían la capacidad de decidir y significar sus vidas. Menos aún de encontrarle algún sentido. Lo uno como manifestación de su no tenencia de espacio (posición como lugar material), y lo otro como indicador de su falta de opinión (posición como sitio de las ideas), tal infantilización o desconocimiento de su condición de agentes, esto es de ser poseedores de “intención o conciencia de acción” (Barnard \& Spencer 1998: 595), terminaría por cerrar un círculo alrededor suyo no solo conceptual sino empírico, y que sería observable, irónicamente, en su cotidiana no visibilización ${ }^{2}$.

Visto como problema de vivienda -por su falta y carestía-, e históricamente configurado como expresión de un cierto rechazo al trabajo -por

\footnotetext{
${ }^{1}$ Punto recientemente reforzado por Delgado, su rescate de Kant a propósito de que el espacio sería la "condición de posibilidad de los fenómenos”, o de que "el concepto de posición es absolutamente simple, y se identifica con el concepto de ser en general”, vendría a remarcar esta perspectiva dada la asociación entre ausencia de lugar, la no cristalización en propiedad de un fenómeno y su consecuente inexistencia (Kant, en Delgado 2007: 67-68).

${ }^{2}$ En antropología, una de las más desafortunadas intervenciones en esta línea, es la del norteamericano Harris, quien llegó a afirmar que no sería posible "esperar que los participantes de los estilos de vida expliquen sus estilos de vida [dado que] la conciencia cotidiana no puede explicarse a sí misma” (1994: 13).
} 
la no disposición del espíritu que lo valora como bien social ${ }^{3}$-, lo mismo podría aplicarse a su contemporánea comprensión como una carrera moral del descrédito y en dirección a los bordes de la sociedad -por la pérdida del rol social asignado en manos del self espontáneo (Berho 1999/2000) ${ }^{4}$-, toda vez que al enfatizar en lo que se abandona o a lo que se puede llegar, deja en segundo término, o suspendida como mínima situación liminal, la experiencia misma de la errancia y los significados que a ella y desde ella se otorga por parte de quienes diariamente la vivencian. Grueso adelgazamiento, la marcación de este tipo de abordaje de tan paradójico modo intenta hacer hincapié en la no observación de su fenómeno, aunque parezca de perogrullo, desde su fenómeno mismo, es decir con cargo a un punto de vista émico capaz de concentrarse en el viaje que toda situación liminal supone y que no solo sería, siguiendo al británico Turner, una línea o límite demarcando etapas (1981: 108). Rica, creativa y abierta frontera a la manera en que el antropólogo e historiador Michel de Certeau y el también antropólogo Renato Rosaldo entienden los márgenes ${ }^{5}$, el tránsito, y ya no únicamente la transición de uno a otro lado de la liminalidad, apuntaría, según su condición de viaje, más que a lo sincrónico o acrónico de esos puntos ya deslindados en el mapa, la partida y meta de una carrera en este caso, a la diacronía que, como apunta Delgado, convertiría "una articulación temporal de lugares en una secuencia espacial de puntos” (2007: 69).

Equívoco imputable al francés Marc Augé (1998) cuando a propósito de la distinción entre lugar y no-lugar concibe a este último como "lugar de paso" y no como "el paso por un lugar" dada la carencia de marcas y memoria que los definiría (Delgado 2007: 69), también lo sería, pero de

\footnotetext{
${ }^{3}$ Efecto asociado a la organización del trabajo y la pirámide social de la colonia dada la exclusión que de los colonos pobres y la población mestiza hacía, su acumulación al margen del sistema de encomienda como una creciente reserva de mano de obra, habría sido su fuente y la responsable, en primer término, de tal lectura (Góngora 1966, 1971; Salazar 1990; Bengoa 1988; Araya 1999).

${ }^{4}$ En camino hacia una nueva identidad que se va distorsionando, según el antropólogo chileno Marcelo Berho, ésta iría hacia la predominancia del sí mismo espontáneo, "pero en una versión dislocada del ideal social y cultural que se traduce en autoabandono y decadencia, otras veces en obstinación y resignación autocomplaciente, antes que en cultivo del ego y en profundidad moral” (1999/2000: 47).

${ }^{5}$ Afirmando que “cada cultura prolifera sobre sus márgenes”, De Certeau sitúa en ellos el lugar en que se producen las "irrupciones, a las que se designa como 'creaciones' relativas a los estancamientos [y que] en el imaginario oficial, figuran a título de excepciones o de marginalismos” (1999: 196), reducción que, insistirá más tarde Rosaldo, no alcanza a esconder su magnitud y persistencia, y tampoco el desafío que abren a la comprensión: "Aunque la mayoría de las tipificaciones metropolitanas continúan suprimiendo las zonas fronterizas, las culturas humanas no son por necesidad coherentes, ni tampoco son siempre homogéneas. Con más frecuencia de lo que creemos, nuestras vidas cotidianas se entrecruzan por las zonas fronterizas [de forma que] junto con nuestras identidades culturales en apariencia transparente, esas fronteras no deben considerarse como zonas transicionales de análisis vacío, sino como sitios de producción cultural creativa que requiere de investigación” (1991: 190-191).
} 
distinto modo, del aludido Berho cuando no repara, como se dijo, en el sentido del viaje expresado con y a través de sus vidas por parte de los torrantes, las personas en situación de calle que durante el último tiempo ha venido estudiando en la sureña ciudad de Temuco (1998, 1999/2000, 2003, 2007). Sí observado por el sociólogo chileno Gonzalo Falabella (1970) y los ya presentados Gabriel Salazar (1990), José Bengoa (1988), y otra vez Salazar en un trabajo en coautoría con Julio Pinto (2002a; 2002b), sus lecturas de la salida del campo de vastos contingentes de población en distintos momentos de nuestra historia no solo como medio para la consecución de empleo, sino también como escenario y destino de su gradual transformación identitaria, les permitiría, deteniéndose en la dimensión más microscópica de la vida social, ampliar el rango de mirada hacia su comprensión como parte de procesos mayores que, no por estructurantes y globales, necesariamente han de entenderse como privando a sus actores de su presente, local y temporal, vale decir de la posibilidad de significarlos y por su parte también estructurarlos en el hecho mismo de vivirlos.

Relación vectorial en más de un sentido, los desplazados migrantes agrícolas a los que estos investigadores se refieren y que no son, claramente, las mismas personas que en la actualidad se encuentran en situación de calle, como éstas, también se habrían enfrentado a presentes tensionados por diversas fuerzas y, por ende, plausibles de observar a distinta escala. Fenómeno de tal suerte ligado a la incapacidad de la hacienda y la pequeña propiedad de retener con trabajo a la creciente población campesina de nuestro país -y que habría sido resultado, amén de otros factores, de un lento proceso de capitalización y de los vaivenes de la inversión sectorial y los impactos y movimiento del capital extranjero-, más acá, es decir más cerca de su vivencia por parte de quienes debieron salir a la ruta a tentar por mejor fortuna, tal como con los cortes estratigráficos de la arqueología, permitiría ver otras dimensiones del mismo, igual y distintamente importantes en su construcción. La expansión y contracción del mercado del trabajo ocurrida a comienzos del siglo XX en los Estados Unidos, Argentina y Chile, y contextualmente abordada por el sociólogo chicaguense Nels Anderson (1923) ${ }^{6}$, el periodista argentino Osvaldo Baigorria (1998) y el ya anotado Falabella (1970) en sus investigaciones acerca de las específicas figuras de hobos, crotos y torrantes, iría en esta línea al permitir apreciar mérito de sus estudios e independiente de sus enfoques e interpretaciones-, cómo una realidad se desarrolla en varios planos, y más porque en su intento por situar sociohistóricamente la emergencia de estos sujetos, la vivencia de su particularidad no termina adelgazada y tampoco sus protagonistas que continúan, más o menos, al centro de su interés de conocimiento.

Sabedor de ello este último, de modo permanente establece lazos entre la huella, o esa singular vida en el camino desarrollada por estos ca-

\footnotetext{
${ }^{6}$ Importante como el primer estudio sistemático del tema, el de Anderson también lo es por la mirada interior que alcanza dado el hecho que él mismo, como su padre, un migrante sueco, fueron hobos en su juventud.
} 
minantes y que él interpretó como una suerte de comunismo de subsistencia por su mancomunado sistema de compartir bienes y servicios; el torrante, o el migrante agrícola que en su larga búsqueda de empleo durante el pasado siglo fue encontrándose con otros y desarrollando, en su interacción, aquel sistema en movimiento; y el contexto, económico, político y social, que a nivel nacional e internacional habrían hecho posible, o determinado en sus palabras, su emergencia como estrato. Realidad en varios planos, abarcarla por separado no ayudaría a apreciarlo, tal como él advierte, sino "como un hombre marginal, debido a su dialecto especial, su no común y ‘desviadas' normas de conducta, y su desempleo crónico. [Y] no sería considerado un producto de una sociedad en la que es explotado por capitalistas, como cualquier otro trabajador" (Falabella 1970: 87). O lo mantendría, siguiendo su argumento, como objeto de interés por su exotiquez, pero no de atención como parte, y no al margen, de la sociedad.

Distinción de frontera en el doble sentido del establecimiento de límites (frontera como delimitador/generador de categorías discretas, a la manera en que el francés Pierre Bourdieu critica su concepto) ${ }^{7}$ y de su propia transgresión (frontera como espacio desbordado, de acuerdo al modo en que De Certeau y Rosaldo la reformulan) ${ }^{8}$, articulados aquí por el contenido que refieren y a través de su misma doble perspectiva, no solo dejan ver sus taxonomías -la existencia de diferentes estratos sociales, por ejemplo-, o las relaciones mediante las cuales podría darse su vinculación -como la de explotación, que mientras hace de uno un explotador del trabajo del otro, evita que el otro, dada su peculiaridad, sea entendido como marginal-, sino que hacen posible el reconocimiento de algunos de los muchos elementos de su propia incontención y porosidad como universos cerrados. La anotada rotulación, en este sentido, del torrante como producto de la sociedad y no como, o también, agente de ella, conviviendo a pocas páginas de distancia con otras que reconocen sus acciones como un "esfuerzo” consciente, políticamente intencionado "por crear una sociedad no alienada”, o alentando "a otros obreros a hacer su pequeña revolución y unirse a la huella”, aparecen en tal dirección (Falabella 1970: 106). Igual cosa la alusión a la asimetría entre una entidad mayor, entendida como estructurante -esto es "el proceso de desarrollo/subdesarrollo sectorial [que]

\footnotetext{
${ }^{7}$ Apuntando al ejercicio de demarcación como el acto mediante el cual se introduciría "por decreto una discontinuidad decisoria en la continuidad natural” del mundo de las cosas (Bourdieu 2001: 88) y que como todo arbitrio sancionaría, santificaría y consagraría sus construcciones "haciéndolas existir como dignas de existir [o] como conformes a la naturaleza de las cosas 'naturales'” (ibid: 89), este autor llama la atención con respecto al sentido bidireccional de tales construcciones, afirmando que "la realidad es absolutamente social y las clasificaciones más naturales se apoyan siempre en rasgos que no tienen nada de natural y que en parte son producto de una imposición arbitraria, es decir, de un estado anterior a la relación de fuerzas en el campo de las luchas para la delimitación legítima. [Por lo que, agrega,] la frontera, ese producto de un acto jurídico de delimitación, produce la diferencia cultural en la misma medida que ella es producto de esa diferencia” (ibid).

${ }^{8}$ Ver Nota 5.
} 
crea el estrato torrante y el contexto social y político general en el que su formación de clase ocurre” (ibid: 93)-, y otra menor, no obstante ello en pugna con y relativamente alterna a aquélla -o esos sujetos individuales deviniendo identitariamente en actor colectivo, es decir como torrantes en la huella-, que lo remarcaría aún más dadas las filtraciones que para la señalada unidireccionalidad de su producción como estrato tendría tal gesto de resistencia política y cultural.

Mundo(s) de frontera y no frontera(s) del o los mundos, tal como tácitamente señala el historiador Mario Góngora, la ampliación de su entendimiento como espacio incorporado y punto de vista en y a través del cual ver, sería la que le permite apreciar al territorio fronterizo como el área en sí misma que es, en este caso escenario de permanente atracción para un gran número de personas que desde los albores de nuestra historia fue dando forma ahí al disímil fenómeno del vagabundaje (1966, 1971), y que aunque distinto al observado hoy en la ciudad, acá se lo presenta como una de sus líneas de desarrollo anterior, más aún por la relación de otredad absoluta que como espacios y contenidos polares representarían: lo nomádico como oscilación e inestabilidad, de un lado, y su superación por el urbano emplazamiento, del otro (Delgado 2007: 63-64). Documentada suficientemente por la historiografía, la razón, empero, de su inclusión acá, guarda relación con el modo en que los significados asociados al fenómeno se han venido construyendo, de espaldas al mismo y como una cosa dada, y no en correspondencia con las circunstancias contextuales, simbólicas y materiales, desde donde surgen como construcción.

Palabras que enuncian contenidos, pero que también renuncian a otros mientras lo hacen, su fuerza decidora, como en la colonia cuando la oposición trabajo/ocio se entendió y no entendió como cesantía, deja ver la existencia, en otro plano, de enfrentamientos no únicamente ocurridos al nivel de su materialidad, y que fundamentales en su construcción, también lo son a la investigación. Definida como heteroglosia, la característica que señala al lenguaje como un reducto inestable, dinámico y en constante diferenciación a raíz de las disputas de uso y significado dadas entre los grupos, de muchos modos diversos, que en él se relacionan, a estos efectos podría ayudar a comprender las transformaciones que con este fenómeno se han venido dando, en especial si volviendo al período colonial se tiene el mínimo espacio, social y laboral, asignado a un vasto sector de la población y el giro semántico que hizo de esa masa de desocupados moviéndose tras empleo, primero vagabundos, y después ociosos vagabundos.

Cesantía y no simplificada tendencia al ocio, aquella histórica promoción del vagabundeo que solo unos pocos reconocieron y que hoy también podría observarse en el adelgazamiento de su complejidad hasta llevarlo a ser un problema casi únicamente de techo -y que aparece como base del llamado sinhogarismo cuando lo remarca en términos de su estructural carencia, como exclusión, o de la desafiliación de estas personas, como metafórica expresión de su falta de hogar (Bachiller 2007)-, tiende a olvidar la creación de realidad a través de las palabras, no obstante, como apunta 
Bourdieu en relación a su mutua influencia, éstas mismas lo sean de aquélla. Así, si bien toda clasificación produciría "la diferencia cultural en la misma medida que ella es producto de esa diferencia” (2001: 89), el hecho de que la correlación de fuerzas, materiales y simbólicas, de esa lucha por la delimitación legítima sea lo inequivalente que es, plantea el doble riesgo de su reducción y expropiación, como poder aplicado, cada vez que en la mesa de la política pública, y en una ironía de la exclusión, se sientan investigadores y planificadores -Ciencia y Estado de otra forma- a discutir acerca de sus hallazgos y acciones a seguir, sin que en esa conversación estén presentes, precisamente, los excluidos.

Lucha de clases también acá, el posicionamiento de los investigadores como árbitros de todas las materias no solo los inhabilitaría, según este pensador, “para captar la lógica propia de una lucha donde la fuerza social de las representaciones no es necesariamente proporcional a su valor de verdad" (ibid: 93), sino que actualizando el escepticismo radical del físico austriaco Paul Feyerabend respecto a la ciencia y su carácter privilegiado para la producción de conocimiento (2001), trae a colación la propuesta del antropólogo catalán Oriol Romaní en orden a entender que más que culturas de la marginación, habría que hablar de retóricas de la marginación de forma que el acento estuviese no ya en el fenómeno como tal, o no solo, sino en el ejercicio de visualización, o también, que lo denota y ayuda a construir. Así, a su complejidad interna, como suma de acciones y significados, habría que agregar el modo con que se les define (produce), esto es las (cambiantes) formas cómo se les sitúa dentro o fuera de los márgenes establecidos, entendiendo que "una de las grandes tareas que han tenido que realizar siempre los humanos ha sido la de definir los límites que se van imponiendo al caos, y la de gestionar la sociedad de acuerdo con estas definiciones de la realidad” (1996: 303).

Intento de establecer un campo de estudio para la antropología, además de remarcar la variedad de discursos existentes sobre la marginación -como las perspectivas histórico-institucionales que la ven emerger de la mano de procesos de normalización, los análisis estructurales que sitúan la condición de marginado en su determinación infraestructural, la teoría dependentista que la pone como efecto del desarrollo capitalista en países cuya urbanización no guarda relación con su industrialización, o los enfoques sistémicos, procesuales, interculturales, simbólicos, u otros-, según este autor debieran tenerse en cuenta al menos cinco distintos niveles en la configuración de este fenómeno, a saber, los procesos de exclusión social ligados a las transformaciones económicas; las elaboraciones culturales de quienes sufren estas situaciones con respecto a sus estrategias de resistencia y/o adaptación; los discursos sociales, tanto académicos como populares, y su amplificación mediática; su incidencia en las estrategias de resistencia y/o adaptación señaladas; y, por último, las prácticas y discursos de los llamados innovadores culturales, esto es de quienes manifiestan situaciones de conflicto en relación a los límites sociales en ámbitos como la sexualidad, uso de drogas, identificación étnica u otros. 
Advertencia sustantiva la de Bourdieu e interesante la propuesta de Romaní, la fuerza magnética de la frontera atrayendo un amplio rango de personas y con su arribo y actividad su propia aparición en el mapa, también habría supuesto, en un juego de miradas y significados impuestos, el retorno a su estatus de sitio vacío (según el sentido latino que apunta a la cesación del trabajo e inactividad), esta vez, sin embargo, por su ocupación por parte de esta población ya entonces signada como vagabunda y malentretenida. Marca sobre lo rural de igual modo que antes lo fue con la población indígena y el resto del bajo pueblo, en términos espaciales, escribe Alejandra Araya (1999), ello dibujará un camino que iniciado en la criminalización de este sector de la población y situado en el campo como el lugar de su habitación y amparo, con el tiempo terminará en Santiago, como miedo, una vez que la plebe arribe allá. Entonces, mediados del siglo XVIII, tal reacción traerá consigo su progresiva reducción como problema social, y de seguridad social, de forma que sus muchos orígenes -ya sean históricos como fenómeno sociocultural, o individuales como resultado de trayectorias vitales específicas-, irán quedando a un lado de la mano de una mayor atención por la expresión material de su realidad, esto es la pobreza de sus condiciones de vida. Homeless, sin techo o sin domicilio fijo, o personas en situación de calle más ampliamente, verán ascender así a categoría nominal y fundante uno de los componentes que describen su realidad: el techo, o la falta de él. De paso, tal vaciamiento también los incluirá a ellos, minusvalorados como actores, invisibilizados societaria y comprehensivamente, otra vez al margen de su propio fenómeno.

Foco, desde una cierta perspectiva, en lo material en desmedro de lo simbólico, desde otra, si se aplica lo apuntado por el filósofo chileno Humberto Giannini (2004), podría ser éste, menos visible, el responsable de su actual conceptualización como problema ligado a la falta de techo: no la pobreza como su manifestación sensible (o no solo ésta), y sí los invisibles códigos que distinguen los comportamientos socialmente aceptables de los que no lo son (o también aquéllos), el entorpecimiento de las rutas o rutinas de la calle por parte de esta población, (también) podría ayudar a entender este contemporáneo giro. Dicotomía aparente, tal como en el siglo XVIII la transición económica hacia formas de producción capitalista y su correlato discursivo que descubre a la sociedad chilena transitando hacia una modernidad ilustrada, racional y ordenada ayudan a entender el fenómeno del vagabundaje como un asunto relativo al ocio (Araya 1999: 17), su insistencia, vale decir que se entienda que se está ante un fenómeno complejo, no reducible a una u otra dimensión y tampoco correctamente estimable si se lo hace solo desde la posición del especialista, o contra sus actores, también podría redundar en lo mismo. Y ello, regresando a Bourdieu, podría ocurrir cuando la oposición entre realidad y representación sea superada, esto es cuando se incluya "en lo real la representación de lo real, o más exactamente la lucha de las representaciones en el sentido de imágenes mentales, pero también de manifestaciones sociales destinadas a manipular esas imágenes mentales” (2001: 88). 
De un lado, normatividad invisible de muchas maneras violentada; de otro, persistencia de su expresión material al abordarlo; entremedio, una confusión de situaciones distintas a partir de intereses también diferentes; conjunto de cosas, en suma, que también habría ayudado a reducir su entendimiento hasta llevarlo a ser, incluso, un problema de seguridad social. Observable a lo largo del siglo XX en el intento del Estado chileno de hacerse cargo de la llamada cuestión social, hacia 1941 se lo puede ver como fundamento para la creación y mantención de instituciones de asilo y protección de la población adulta en situación de calle, esto es la intención de "asegurarles la ayuda del Estado y evitar las exhibiciones públicas de su desmedrada condición personal [a quienes] ejercen la mendicidad sin permiso y que, en razón de ser lisiados o valetudinarios, no tienen aptitudes para el trabajo” (Mideplan 2005: 27). Extracto de un Proyecto de Ley sobre represión de la vagancia y la mendicidad pronunciado como Mensaje ante el Parlamento el 12 de septiembre de 1941 por Pedro Aguirre Cerda, Presidente de la República entonces, y parte, como se indicó, de su arribo al Estado como preocupación pública, y no ya como un asunto únicamente individual que eventualmente se atiende con acciones de beneficencia y/o de vigilancia y encierro, en este texto seleccionado, no obstante pueda no parecerlo, conviven el afán de atender socialmente a la población que no puede hacerlo por sí misma, el de regular el uso de los espacios públicos y el de evitar el afeamiento de la ciudad en correspondencia, estos dos últimos, con la distinción aportada por Giannini entre vida en la calle y vida domiciliaria/actividad laboral (2004: 40), y a través, ahora como conjunto, de una acción normalizadora de represión social a la manera en que Foucault describe e interpreta el internamiento de la edad clásica (1976: 93-94).

Esa una respuesta, con la realización en julio de 2005 del primer Catastro Nacional de Personas en Situación de Calle por parte del Ministerio de Planificación y que arrojó la existencia de 7.254 personas viviendo y durmiendo en las calles de nuestro país, se está ante otra, esta vez con el oficializado interés de propender a su incorporación a los beneficios sociales del Estado. Paso adelante en el reconocimiento de su heterogeneidad y la difícil tarea de dimensionarla dado su carácter flotante, también lo parece la relativa apertura, aunque incipiente y ella misma oscilante todavía, a su condición de agentes. La afirmación de que "lejos de ser sujetos pasivos y 'vulnerables' que meramente sobreviven, son capaces de negociar activamente sus condiciones de vida, adaptarse y reaccionar frente a los obstáculos que encuentran a diario en el intento de 'hacer hogar', aunque sea en la calle” (Mideplan 2005: 78), avanza en esa línea. Su rotulación, empero, como problema y la asunción por parte del Estado de la tarea de darle solución, no deja mucho margen. Tampoco a cómo entiende la perspectiva de derechos cuando en el afán de propender a "su plena integración a los beneficios del progreso” (ibid: 11), ello deja ver una cierta idea uniformadora de la realidad social y cultural que no alcanza a preguntarse por los sujetos que dan forma y fondo a este fenómeno, no obstante la categoría que levanta, personas en situación de calle, parezca estar a mitad de camino entre un promisorio interés por el carácter en construcción de su proceso identitario y un aún convencional énfasis en su condición sin techo. 
Avances hasta acá en el reconocimiento de la interconexión de los fenómenos y la necesidad, por tanto, de sumar y no oponer perspectivas, aún restaría una mayor apertura hacia su carácter en proceso, más aún si, por una parte, ya ha habido una relativa aceptación de la no unilinealidad de los fenómenos sociales, o recursión como señala la teoría de la complejidad al principio según el cual "el producto/efecto se convierte en productor/causa de lo que produce” (Gómez García 1996: 9) ${ }^{9}$ y, por la otra, se trata de fenómenos en espacios como los urbanos signados por el movimiento y la inestabilidad y sin perjuicio de lo cual, como apunta Delgado, también haya ahí una cierta estructura social, pero una no finalizada, "rugosa, estriada y, ante todo, en construcción” (2007: 89-90). Esa todavía una deuda, también lo sería la aceptación de que a todas las personas les asiste la capacidad, en tanto sujetos de cultura y a través de sus acciones, de conservar y/o modificar el estado de las cosas, entendiendo, como ha aportado un gran número de autores y aquí se pone en boca del turinés Carlo Ginzburg, que al igual que "la lengua, la cultura ofrece al individuo un horizonte de posibilidades latentes, una jaula flexible e invisible para ejercer dentro de ella la propia libertad condicionada" (1997: 18). Horizonte el de la cultura y la lengua, pero horizonte abierto, como la frontera, a la infinitud exponencial de sus combinaciones, lo siguiente sería, continuando con este microhistoriador, reaccionar al incompleto retrato que ha hecho de la cultura popular una pasiva e improductiva receptora del excedente cultural de las clases dominantes, un implícito cúmulo de valores no del todo alternos o su infranqueable equivalente otro. En otras palabras, entender la subalternidad como alternidad.

Flanco aún por recorrer, los avances y vacíos anotados buscan insistir en que si bien la situación de calle moldea la identidad personal de quienes en ella se encuentran, no sería inerme a su presencia que también la modela a ella. Lo mismo la estructura de relaciones sociales y la conducta de los sujetos, mutuamente influenciables, según acota el español José Ignacio Porras (2005) y refrendan los testimonios recogidos en el ya citado catastro (Mideplan 2005), toda vez que contrario a la idea de desafiliación -central al sinhogarismo y un obstáculo para "analizar las afiliaciones que las personas establecen una vez inmersos en los contextos de calle" (Bachiller 2007: 2)-, entre quienes están en esta situación sí existirían lazos, más o menos a la manera en que la antropóloga Larissa Lomnitz entiende las

\footnotetext{
${ }^{9}$ Definida por Morin como el "proceso en el que los efectos o productos al mismo tiempo son causados y productores del proceso mismo, y en el que los estados finales son necesarios para la generación de los estados iniciales”, esta característica de relación que él llama de recursividad (1988: 111), para el catedrático de filosofía de la Universidad de Granada, el español Pedro Gómez García, daría más alcance al principio de retroacción agregando las ideas de producción y autoorganización, permitiendo pensar la existencia de esa actividad como no únicamente repetitiva o conservadora: "los individuos humanos -al respecto diceresultan de un sistema de reproducción, de la especie, pero ese sistema no puede reproducirse sin la actividad reproductora de los individuos. Igualmente, producimos la sociedad con nuestras interacciones individuales, pero el sistema sociocultural produce nuestra humanidad individual mediante la cultura y el lenguaje” (1996: 9).
} 
redes sociales, esto es campos de relaciones entre individuos caracterizados por su difuminación y superposición, el intercambio vertical u horizontal de bienes, servicios e información, su constitución a partir de centros ocupados por ellos mismos que las definen en tipo y número, y que ordenan en una suerte de mapas cognitivos a partir de los cuales se mueven según la distancia social o confianza que ellos y su grupo de pertenencia determinan (2000).

Más flexible conceptualmente que la noción de estructura social, su uso, como se dijo, busca remarcar la posición de agentes de quienes han sido insistentemente negados en ella y que, si se aplican las ideas de la norteamericana Sherry Ortner, aún acá la ejercerían, sea como proyecto o sea como poder, y reproduciendo o transformando con ella las situaciones dadas y, en ningún caso, siendo inocuos en sus efectos (2006: 139). O, si se quiere, pudiendo distinguirse por la orientación a un objetivo y la autoconciencia de sí mismos, esto es como acción propiamente tal y no solo como mera conducta (Keane 2003: 231); o como actos de elección y decisión cuyo ordenamiento sistemático sería la organización social (Firth 1971: 40); o dando forma a tramas de significación por ellos mismos, y por propia mano, entonces, insertándose en ellas, esto es en la cultura que sería esa urdimbre (Geertz 1997: 20). En suma, teniendo en cuenta que "rasgos estructurales tales como 'cultura', 'sistemas sociales', ‘estratificación social' o ‘roles sociales’ establecen condiciones para su acción pero no determinan su acción” (Blumer 1962: 152), máxime en el espacio urbano comprendido, a estos efectos, como aquel que "conoce la heterogeneidad inmutable de las acciones y de los actores [suerte de] proscenio sobre el que se negocia, se discute, se proclama, se oculta, se innova, se sorprende o se fracasa” (Delgado 2007: 15).

Como sea que fuere, la articulación en estas páginas de un marco conceptual en relación a, y no aparte de, una selección de los análisis y desarrollos que se han hecho en torno al fenómeno de la situación de calle, ha querido representar, como ejercicio plausible, una cierta forma en que sus retóricas también lo han venido construyendo. La académica ésta, otras en otros planos a diario también lo hacen, en la calle por ejemplo a propósito de la interacción entre vecinos/as, esta población y los viandantes. Acceder a esas conversaciones, por tanto, y luego textualizarlas a la manera en que el inglés Nigel Rapport las entiende (1997) ${ }^{10}$, también es parte de esta investigación. Reconocimiento en ello de la agencia discursiva de quienes ocupan los espacios públicos como lugar en curso, esto es en una mo-

\footnotetext{
${ }^{10}$ Afirmando, Rapport, que la conversación es “el vehículo más importante para mantener la realidad; [dado que,] operando en el sentido del mecanismo conversacional el individuo protege y confirma la consistencia de su mundo" (1997: 180-181), este autor sostiene que "si juntamos en un texto las voces distintas, diversas e incompatibles y las epistemes de un medio social de modo tal que subraye su irreconciabilidad y que su interacción pueda describirse como 'escribiendo como conversación', entonces todavía puede ser posible aseverar que 'la conversación epistemológica de este texto es como la conversación cotidiana de la vida social”” (ibid: 179).
} 
dalidad en movimiento y en proceso ${ }^{11}$, también lo es del posicionamiento ético del investigador en cuanto a poner sus interpretaciones al centro y en diálogo, y no fuera (o encima), de las otras que al respecto hay. No en la altruista forma (por decir lo menos) de querer dar voz a los sin voz -lo que vendría a ser, según advierte Stephen Tyler, una expropiación pues toda representación sería un acto de represión (1998: 289)-, sino de propender a un diálogo reflexivo que lo entienda como un "proceso de interacción, diferenciación y reciprocidad entre la reflexividad del sujeto cognoscente -sentido común, teoría, modelos explicativos-y la de los actores o sujetos/ objetos de investigación" (Guber 2001: 53). Reflexiva, entonces, en el sentido de encontrarse dos maneras equivalentes de entender el mundo -a estos efectos, las muy concretas de los interlocutores pero también las más abstractas que están detrás suyo, y que harían parte de sus otros diálogos como sujetos no unarios (Tedlock 1998: 285)-, ello se plantea como paso para su mutuo reconocimiento, aceptación y reaprendizaje, o en otras palabras, como la empática intención de ver como si el otro viera a través.

Pretencioso afán, de fondo intenta remarcar las muchas maneras cómo se imagina a esta población sin capacidad de incidir, no ya en sus propias vidas sino, tampoco, en las dinámicas y contextos urbanos que ocupan. Somos todos iguales pero algunos lo somos más, irónicamente escribe, o más o menos, George Orwell en su conocida novela de crítica política Rebelión en la granja (2003), insinuando, con ello, que la noción de ciudadanía, excluyente por definición ${ }^{12}$, no solo sería asunto de explícitas, formales y definitivas decisiones sino, más bien y también, de gran inestabilidad y permanente modificación. Activos conocedores de ello, aunque no reconocidos por ello, las personas en situación de calle, como cualquier otro habitante o transeúnte de la ciudad, también incidirían, y mucho, en los espacios urbanos a partir de su desplazamiento y asentamiento, la negociación constante de acuerdos (y desacuerdos), o la generación de circuitos, redes y relaciones ${ }^{13}$. Que no los veamos en el curso de lo cotidiano, se los

\footnotetext{
${ }^{11}$ Como lugar en curso, esta noción busca complementar la idea de espacio con que De Certeau refiere al lugar practicado (2000: 173), toda vez que si bien éste reconoce las movilidades que en él operan y lo hacen funcionar como un no-lugar que en tanto potencia, o posibilidad de lugar, le sería imposible cristalizar en sitio o punto en el mapa, no deja de observar sus travesías vectorialmente, como recorridos y desde una posición externa. Mientras que situados sobre una suerte de cinta de movimiento, vale decir en su movimiento, su noción apunta al curso del mundo de las cosas, esto es a su permanente estar siendo -0 “estar siendo-ocurriendo”, como podría agregar el antropólogo chileno Peter Wild (2001) , y que aplicado a los modos de realización de la vida en situación de calle, busca reforzar su doble carácter en movimiento y en proceso.

${ }^{12}$ Reconociendo las diferencias entre grupos, épocas y sus propios énfasis, el carácter excluyente de la noción de ciudadanía guardaría relación, según el español Ricard ZapataBarrero, con el hecho de que "su semántica ha connotado constantemente un privilegio y un límite social, ético, político y económico frente a las demás personas no incluidas dentro de su alcance semántico" (2001: 23).

${ }^{13}$ Ciudad construida desde muchas veredas, a una similar conclusión arriba, por ejemplo, el brasileño José Cantor Magnani, de la Universidad de Sao Paulo, en el marco de la Mesa
} 
haya encerrado real y metafóricamente a lo largo de la historia como efecto de sendos procesos ordenadores y de normalización (Foucault 1976; Araya 1999), o no se los mencione en la literatura especializada que trata y no trata del tema, es otra cosa, máxime si como se ha dicho, la calle, a diferencia de la vida domiciliaria y la actividad laboral, estaría regida por un tipo de normatividad invisible orientada a mantenerla despejada como ruta, y dispuesta y libre para su rutina (Giannini 2004: 40). Anónima pero fuertemente gobernada, doble razón, entonces, para comenzar a reconocer la aguzada capacidad de negociación que se requeriría para ocupar un sitio que no se debe, sosteniéndose no solo en el ejercicio de hacerlo, sino en el más difícil de aparecer no haciéndolo (Mideplan 2005: 51).

Así, si el referido Manuel Delgado, por ejemplo, no los explicita como viandantes en tránsito ni como ocupantes asentados de la urbe, esto es ni como parte del afuera más difuso ni como parte del adentro construido a pesar de haber desarrollado una sólida argumentación que podría permitir su ubicación tanto en uno como en otro dado el hecho que, en sus palabras, ambos serían "en esencia campos móviles que no tienen por qué corresponderse con escenarios físicos concretos” (2007: 32), lo que restaría, más que intentar determinar cuál de ellos cabe a su estatus de situación de calle, es reconocer la persistencia de esta invisibilidad y, desde ahí, preguntarnos a qué se debe y cómo hacerle frente.

Cercano, entonces, a una teoría de la agencia capaz de reconocer a las personas como sujetos de cultura cuyas acciones -intencionales y conscientes, repetitivas o innovadoras, y cargadas de significado en uno u otro sentido-, constituyen los cotidianos modos en que se produce la conservación y el cambio (De Certeau 1999; Barnard \& Spencer 1998), el marco de este trabajo también es próximo a la visualización de que lo que encara el etnógrafo "es una multiplicidad de estructuras conceptuales complejas, muchas de las cuales están superpuestas o enlazadas entre sí [y] que son al mismo tiempo extrañas, irregulares, no explícitas” (Geertz 1997: 24), más aún considerando que "la vida social en espacios públicos se caracteriza no tanto por estar ordenada, como por estar permanentemente ordenándose” (Delgado 2007: 90). Doble caracterización que apunta, por un lado, a un enfoque interpretativo al modo de la descripción densa, esto es como un reconocimiento de niveles otros de significación en permanente emergencia, y la necesidad de acceder a la complejidad interna de los fenómenos como suma de acciones y significados, o hechos y discursos de acuerdo a cómo Geertz opone complementariamente el fluir de la conducta, como acción social, y el lugar que ocupan en estructuras operantes de vida, como discurso social (1997: 30); y sin olvidar, por el otro, que el escenario de esta observación es lo urbano, necesidad entonces de pensar su abordaje como una etnografía de la calle que también lo sería de lo inestable e incierto, paso previo para el establecimiento de una antropología de la vida pública (Delgado 2007: 124-125). Marco previsto como un ejercicio antropológico a distinta escala, aquí se lo ha imaginado como un transcurrir desde el pequeño fenómeno que llama nuestra atención por enigmático, lo microscópico, hasta su engarzamiento con otros, igualmente pequeños, 
junto a los cuales están sometidos a, y construyen, aquellos procesos mayores, lo macroscópico, que estructurantes o no, conforman el escenario espacial y temporal de su ocurrencia y que, en ningún caso, serían importantes solo como contexto y, tampoco, únicamente experienciables por la significación que se les da en el cotidiano. También estructurados ahí, una última pieza es la consideración de lo real, y de la representación de lo real, como una construcción a muchas voces, cuestión que acá se ha señalado como la necesidad de situarlas en diálogo, como retóricas de la marginación (Romaní 1996) ${ }^{14}$.

Relevante, por último, por el reconocimiento de la condición de sujetos que estos hombres y mujeres tienen por sí mismos y que largamente se les ha escamoteado, también lo es por la oportunidad, siguiendo a Delgado, que la apertura a lo inestable y difuso de los fenómenos sociales, y más en

\footnotetext{
${ }^{14}$ A estos efectos pertinente, pero sin espacio para su desarrollo, menciónese los puentes que podrían establecerse, entre otros, con Marcel Mauss (1971), en relación a cómo la noción de persona se ha configurado en el tiempo y en el espacio, y su reducción cuando se la asocia con la de domicilio; con Eduardo Menéndez (1988, 1990), a propósito del céntrico lugar que el alcohol tiene en nuestras sociedades, también entre esta población; con Philippe Bourgois (2004) o Lee Stringer (1999) a propósito de lo mismo, esta vez en torno al consumo de drogas, uno desde su posición de investigador, el otro como homeless recuperado de su adicción; con Jean Baudrillard (2000, 1993), respecto de los efectos de la pérdida de los referenciales reales del trabajo y su constitución como código, ello en vistas a su papel en la configuración del vagabundaje como un asunto relativo al ocio y, desde ahí, con Max Weber (2003) y la ética protestante que lo valora, o con Osvaldo Baigorria (1995) y las muchas otras que lo resienten; con André Comte-Sponville (2001, et al. 2005), en relación a la búsqueda de sentido y felicidad trasuntada, por ejemplo, en el concepto de subordinación sensual que ensaya Bengoa (1988) y da cuenta Falabella (1970) para referir la negativa torrante a abandonar el juego y sus valores asociados; con Enrique Gómez-Correa (1942), a propósito del lugar que la locura ha tenido y perdido en las sociedades y en el tiempo, y lo mismo, entonces, con Michel Foucault (1976, 2000), Thomas Szasz (1994), David Cooper (1985), Franco Basaglia (et al. 1995) y Pablo Egenau (et al. 2005) que lo abordan directa o indirectamente desde sus especialidades, o Diamela Eltit (2003) y Raúl Gómez Jattín (2000) que lo hacen desde sus búsquedas literarias y personales; otra vez con Foucault (1998), ésta en relación con los discursos y práctica de la delincuencia, o con Ian Taylor (et al. 1977), Alejandro Isla (s/f) o Alfredo Gómez Morel (1997) que también lo hacen, los dos primeros desde la discusión teórica y empírica, el último desde su propia vivencia delincuencial; con José Nun (1972) y Anibal Quijano (1973) a propósito de los procesos de marginalidad y exclusión que desde un nivel más estructural han sufrido nuestros países latinoamericanos; con Boris Cyrulnik (2001) respecto a la capacidad resiliente de muchas de estas personas; con Oscar Lewis (1997, 1973), Larissa Lomnitz (2003), Vicente Espinoza (1988) y Carolina María de Jesús (1961), en relación a la cultura de la pobreza en torno a la que el primero investiga, la segunda discute y profundiza desde el conocimiento de los mecanismos de supervivencia de los marginados, el tercero historiza y la última da personal testimonio como cartonera; o, por último, con Manuel Rojas (1991), Diamela Eltit (1983), Cronwell Jara (2004), Jorge Amado (1984), Jack London (1998), u otros escritores que, desde la literatura, han aportado a la construcción de su significado, o Jon Krakauer (1998), Pedro Lemebel (1998) y Genoveva Grisolía (2003), que a su vez lo han hecho desde la crónica periodística y literaria o la poesía.
} 
espacios urbanos, podría conllevar en términos teóricos y metodológicos si se los comenzase a ver como en construcción o en proceso de, y ya no como definitivos. Gesto equitativo y de mínima justicia social, por un lado, y desafío comprehensivo del más alto nivel, por el otro, el emprendimiento de estudios que reconociendo la alternidad de las personas procurase avanzar hacia una más efectiva valoración de su agencia y la complejidad de las realidades sociales, hechas, desechas y contrahechas de muchos modos, aparece como un esfuerzo de la mayor importancia, máxime si se considera que nacida la antropología como empresa para el conocimiento de la otredad lejana, y con el tiempo devenida en disciplina también para el estudio de nuestras modernas sociedades industriales, probablemente tenga en estudios como éste el escenario y el fenómeno que más se aproxima a los dados en contextos tradicionales. Lejos de afirmar, sin embargo, que la carpa en la aldea a la manera que hicieron los grandes prohombres de la etnografía sea una alternativa aplicable aquí, el comportamiento transhumante y de tribu que algunos autores confieren a esta población, ayudando a sostener la alusión a esta cercanía, podría permitir la apertura de otra línea de discusión, esta vez al interior de la antropología y, desde ahí, servir al delineamiento de nuevas herramientas teóricas y metodológicas, amén de la permanente y siempre necesaria reexaminación disciplinar. 


\section{Bibliografía}

Amado, Jorge (1984), La muerte y la muerte de Quincas Berro Dágua, Emecé, Buenos Aires.

Anderson, Nels (1923), The hobo. The sociology of the homeless man, University of Chicago Press.

Araya, Alejandra (1999), Ociosos, vagabundos y malentretenidos en Chile colonial, DIBAM, LOM Ediciones, Santiago de Chile.

Augé, Marc (1998[1992]), Los no lugares: espacios del anonimato. Una antropología de la sobremodernidad, Gedisa, Barcelona.

Bachiller, Santiago (2007), "Recensión crítica. David A. Snow and Leon Anderson. Down on their luck. A study of homeless street people”, en AIBR. Revista de Antropología Iberoamericana, 2(2):388-397. http://www. aibr.org/antropologia/02v02/libros/020204.pdf Consultado 28/09/07.

Baigorria, Osvaldo (1995), Con el sudor de tu frente. Argumentos para la sociedad del ocio, La Marca, Buenos Aires.

Idem (1998), En pampa y la vía. Crotos, linyeras y otros trashumantes, Perfil Libros, Buenos Aires.

Barnard, Alan \& Jonathan Spencer (1998), Encyclopedia of social and cultural, Routledge, G.B.

Basaglia, Franco; Langer, Marie; Caruso, Igor; Szasz, Thomas; Verón, Eliseo; Suárez, Armando \& Guillermo Barrientos (1995[1978]), Razón, locura y sociedad, Siglo XXI, Ciudad de México.

Baudrillard, Jean (2000[1973]), El espejo de la producción, Gedisa, Barcelona.

Idem (1993[1976]), El intercambio simbólico y la muerte, Monte Avila, Caracas.

Bengoa, José (1988), El poder y la subordinación. Acerca del origen rural del poder y la subordinación en Chile, Ediciones Sur, Santiago de Chile.

Berho, Marcelo (1998), "Esbozo para una etnografía del vagabundo”, en CUHSO. Cultura, hombre y sociedad, 4(1):38-43, Universidad Católica de Temuco.

Idem (1999/2000), "Una carrera hacia los bordes de la sociedad”, en CUHSO. Cultura, hombre y sociedad, 5(1):45-56, Universidad Católica de Temuco. 
Idem (2003), "Personas marginadas sin hogar en Temuco; enfoque antropológico aplicado", en Movimiento de campo en torno a cuatro fronteras de la antropología en Chile, Ediciones ICAPI, Guatemala, pp. 109121.

Idem (2007), “Alteridad, reflexividad y cambio cultural. Reflexiones desde una etnografía de las personas sin hogar y el 'sin-hogarismo'”, Ponencia presentada en las V Jornadas de Etnografía y Métodos Cualitativos, 8, 9 y 10 de agosto de 2007, Instituto de Desarrollo Económico y Social (IDES), Buenos Aires. MS.

Blumer, Herbert (1962), “Society as Symbolic Interaction”, en Human Behavior and Social Process: An Interactionist Approach, HoughtonMifflin, Boston.

Bourdieu, Pierre (2001[1985]), ¿Qué significa hablar?, Akal, Madrid.

Bourgois, Philippe (2004), “Crack-cocaína y economía política del sufrimiento social en Norteamérica”, en Humanitas, (5):95-103, Fundación Medicina y Humanidades Médicas, Barcelona. En: http://www. fundacionmhm.org/Mono5/Articulos/edicion12.html Consultado 26/07/07.

Comte-Sponville, André (2001), El mito de Icaro. Tratado de la desesperanza y la felicidad, Antonio Machado Libros, Madrid.

Comte-Sponville, André; Delumeau, Jean \& Arlette Farré (2005), La historia más bella de la felicidad, Anagrama, Barcelona.

Cooper, David (1985), Psiquiatría y antipsiquiatría, Paidós, Barcelona.

Cyrulnik, Boris (2001), Los patitos feos, Gedisa, Madrid.

De Certeau, Michel (1999[1974]), La cultura en plural, Nueva Visión, Buenos Aires.

Idem (2000[1979]), Invención de lo cotidiano. Artes de hacer, Universidad Iberoamericana, Ciudad de México.

De Jesús, Carolina María (1961), Quarto de despejo. Diario de una mujer que tenía hambre, Abraxas, Buenos Aires.

Delgado, Manuel (2007), Sociedades movedizas. Pasos hacia una antropología de las calles, Anagrama, Barcelona.

Egenau, Paulo; Ossa, Luis; Lowick-Russell, Jenny \& Emilia López (2005), "Personas en situación de calle y discapacidad psíquica o mental: reflexiones Hogar de Cristo y Red-Calle”, en Enfermedad Mental, Derechos Humanos y Exclusión Social, Ministerio de Salud, Universidad Central, Hogar de Cristo, Santiago de Chile, pp. 107-126. 
Eltit, Diamela (1983), Lumpérica, Las Ediciones del Ornitorrinco, Santiago de Chile.

Idem (2003[1989]), El Padre Mío, LOM Ediciones, Santiago de Chile.

Espinoza, Vicente (1988), Para una historia de los pobres de la ciudad, Ediciones Sur, Santiago de Chile.

Falabella, Gonzalo (1970), "Desarrollo del capitalismo y formación de clase: el torrante en la huella”, en Revista Mexicana de Sociología, (1):87-118, UNAM.

Feyerabend, Paul (2001), “Cómo defender a la sociedad de la ciencia”, en Polis, I(1):379-387, Universidad Bolivariana, Santiago de Chile.

Firth, Raymond (1971[1951]), Elementos de antropología social, Amorrortu, Buenos Aires.

Idem (1976[1964]), Historia de la locura en la época clásica I, F.C.E., Ciudad de México.

Idem (1998[1975]), Vigilar y castigar. Nacimiento de la prisión, Siglo XXI, Ciudad de México.

Idem (2000[1999]): Los anormales, F.C.E., Ciudad de México.

Geertz, Clifford (1997[1973]), La interpretación de las culturas, Gedisa, Barcelona.

Giannini, Humberto (2004), La reflexión cotidiana. Hacia una arqueología de la experiencia, Universitaria, Santiago de Chile.

Ginzburg, Carlo (1997[1976]), El queso y los gusanos. El cosmos, según un molinero del siglo XVI, Muchnik, Barcelona.

Glasser, Irene (1996), “Homelessness”, en Encyclopedia of cultural anthropology, Henry Holt \& Co, USA, pp. 579-582.

Gómez-Correa, Enrique (1942), Sociología de la locura, Ediciones Aire Libre, Santiago de Chile.

Gómez García, Pedro (1996): “La construcción de la antropología compleja. Etapas y métodos”, en Gazeta de Antropología, 12. En <http:// www.ugr.es/ pwlac/G12_02Pedro_Gomez_Garcia.html_> Consultado 10/ $12 / 07$

Gómez Jattín, Raúl (2000), El libro de la locura, Colección La Casa de la Poesía, Buenos Aires. 
Gómez Morel, Alfredo (1997[1962]), El río, Sudamericana, Santiago de Chile.

Góngora, Mario (1966), “Vagabundaje y sociedad fronteriza en Chile (siglos XVII a XIX)”, en Cuadernos del Centro de Estudios Socioeconómicos, (2):1-41, Universidad de Chile, Santiago.

Idem (1971), "Vagabundaje y sociedad fronteriza en Chile (siglos XVII y XVIII)”, en Estructura social de Chile, Hernán Godoy (ed.), Universitaria, Santiago de Chile, pp. 73-81.

Grisolía, Genoveva (2003), Grotesca, Escritores Independientes, Buenos Aires.

Guber, Rosana (2001), La etnografía. Método, campo y reflexividad, Norma, Buenos Aires.

Harris, Marvin (1994), Vacas, cerdos, guerras y brujas. Los enigmas de la cultura, Alianza, Madrid.

Isla, Alejandro (s/f), "La calle, la cárcel y otras rutinas de los ladrones. Tradición y cambio en el mundo del delito”. En: http://www. urbalvalparaiso.cl/p4_urbalred14/site/artic/20031119/asocfile/ISLA.pdf Consultado 06/09/07.

Jara, Cronwell (2004[1981]), Montacerdos, Ediciones Metales Pesados, Santiago de Chile.

Keane, Webb (2003), "Self-interpretation, agency, and the objects of anthropology: reflections on genealogy”, en Comparative Studies in Society and History, (45):222-248, Cambridge University Press. En: http:// journals.cambridge.org/action/displayAbstract?fromPage=online\&aid= 151905 Consultado 06/09/07.

Krakauer, Jon (1998[1996]), Hacia rutas salvajes, Ediciones B, Barcelona.

Lemebel, Pedro (1998), “La loca del carrito (o 'la marea humana de un caudaloso vitrinear')”, en De perlas y cicatrices. Crónicas radiales, LOM Ediciones, Santiago de Chile, pp. 138-139.

Lewis, Oscar (1997[1959]), Antropología de la pobreza. Cinco familias, F.C.E., Ciudad de México.

Idem (1973[1961]), Los hijos de Sánchez. Autobiografía de una familia mexicana, Mortiz, Ciudad de México.

Lomnitz, Larissa (2003[1975]), Cómo sobreviven los marginados, Siglo XXI, Ciudad de México. 
Idem (2000), "Redes sociales en la esfera privada de las sociedades urbanas latinoamericanas”, en Actas 3er Congreso Chileno de Antropología, Temuco, 9 al 13 de noviembre de 2004, Colegio de Antropólogos de Chile, Santiago de Chile, Tomo I, pp. 67-70.

London, Jack (1998), Los vagabundos, Club Internacional del Libro, Madrid.

Mauss, Marcel (1971), “Sobre una categoría del espíritu humano: la noción de persona y la noción del 'Yo'”, en Sociología y antropología, Tecnos, Madrid, pp. 307-333.

Menéndez, Eduardo (coord.) (1988), Nueva Antropología. Revista de ciencias sociales. Antropología del Alcoholismo, No 34, GV Editores, Ciudad de México.

Idem (1990), Morir de alcohol. Saber y hegemonía médica, Editorial Patria, Consejo Nacional para la Cultura y las Artes, Ciudad de México.

Mideplan (2005), Habitando la calle. Catastro Nacional de personas en situación de calle. 2005, Ministerio de Planificación Nacional, Santiago de Chile.

Morin, Edgar (1988), El Método. El conocimiento del conocimiento, Cátedra, Madrid.

Nun, José (1972), “Marginalidad y otras cuestiones”, en Revista Latinoamericana de Ciencias Sociales, (4):97-128, FLACSO, Santiago de Chile.

Ortner, Sherry (2006), Anthropology and social theory: culture, power, and the acting subject, Duke University Press.

Orwell, George (2003[1952]), Rebelión en la granja, Destino, Barcelona.

Porras, José Ignacio (2005), "Redes. Fundamentos, alcances y expectativas de una iniciativa editorial”, en Redes. Enfoques y aplicaciones del Análisis de Redes Sociales (ARS), Universidad Bolivariana, Santiago de Chile, pp. 5-13.

Quijano, Aníbal (1973), "La formación de un universo marginal en las ciudades de América Latina”, en Imperialismo y urbanización en América Latina, Gustavo Gili, Barcelona.

Rapport, Nigel (1997), "Edifyng anthropoloy. Culture as conversation; representation as conversation”, en After writing culture. Epistemology and praxis in contemporary anthropology, Routledge, London, pp. 177-193.

Rojas, Manuel (1991[1951]), Hijo de ladrón, Zig-Zag, Santiago de Chile. 
Romaní, Oriol (1996), “Antropología de la marginación. Una cierta incertidumbre”, en Ensayos de antropología cultural, Ariel, Barcelona, pp. 303-318.

Rosaldo, Renato (1991[1989]), Cultura y verdad. Nueva propuesta de análisis social, Grijalbo, Ciudad de México.

Salazar, Gabriel (1990[1985]), Labradores, peones y proletarios. Formación y crisis de la sociedad popular chilena del siglo XIX, Ediciones Sur, Santiago de Chile.

Salazar, Gabriel \& Julio Pinto (2002a), Historia contemporánea de Chile IV. Hombría y feminidad, LOM Ediciones, Santiago de Chile.

Salazar, Gabriel \& Julio Pinto (2002b), Historia contemporánea de Chile V. Niñez y juventud. LOM Ediciones, Santiago de Chile.

Stringer, Lee (1999[1998]), Invierno en Grand Central, Debate, Barcelona.

Szasz, Thomas (1994[1961]), El mito de la enfermedad mental. Bases para una teoría de la conducta personal, Amorrortu, Buenos Aires.

Taylor, Ian; Walton, Paul \& Jock Young (1977), La nueva criminología. Contribución a una teoría social de la conducta desviada, Amorrortu, Buenos Aires.

Tedlock, Dennis (1998[1991]), “Preguntas concernientes a la antropología dialógica”, en El surgimiento de la antropología posmoderna, Gedisa, Barcelona, pp. 275-288.

Turner, Victor (1981), La selva de los símbolos, Siglo XXI, Madrid.

Tyler, Stephen (1998[1991]), “Acerca de la ‘descripción/desescritura’ como un 'hablar por'”, en El surgimiento de la antropología posmoderna, Gedisa, Barcelona, pp. 289-294.

Weber, Max (2003[1903]), La ética protestante y el espíritu del capitalismo, Prometeo Libros, Buenos Aires.

Wild, Peter (2001), El estar siendo-ocurriendo siempre no más. Sabiduría inca del sentimiento, Tesis de Licenciatura en Antropología, Universidad Bolivariana, Santiago de Chile.

Zapata-Barbero, Ricard (2001), “Los contextos históricos de la noción de ciudadanía: inclusión y exclusión en perspectiva”, en Anthropos, (191):2340, Barcelona. 